\title{
Crystallographic Angles for Manganese Bismuthide
}

\author{
by W. J. Romanow
}

$\mathbf{R}^{\mathrm{B}}$ ECENT papers by Williams, Sherwood, and Boothby, ${ }^{1}$ Seybolt et al., ${ }^{2}$ Heikes, ${ }^{3}$ and Roberts ${ }^{4}$ attest to the increasing importance of the hexagonal ferromagnetic compound $\mathrm{MnBi}$. Since the magnetic properties of $\mathrm{MnBi}$ crystals are highly anisotropic, it is useful and necessary to have appropriate aids for determining their orientations-a $(00 \cdot 1)$ standard stereographic projection and a corresponding table of crystallographic angles for this structure. The tables of crystallographic angles for the hexagonal system available in the literature ${ }^{5}$ are computed for c/ $a$ ratios greater than that of $\mathrm{MnBi}$ and cannot satisfactorily be used to find the crystallographic angles of $\mathrm{MnBi}$.

A table of angles between the crystallographic planes $(H K \cdot L)$ and $(h k \cdot l)$ was calculated for $\mathrm{MnBi}$ from the formula ${ }^{\circ}$

$$
\phi=\arccos \frac{H h+K k+1 / 2(H k+h K)+3 / 4(a / c)^{2} L l}{\frac{\left(H^{2}+K^{2}+H K+3 / 4(a / c)^{2} L^{2}\right)\left(h^{2}\right.}{\left.+k^{2}+h k+3 / 4(a / c)^{2} l^{2}\right)}}
$$

on an IBM Type 650 Magnetic Drum Data Processing machine. The lattice constants used are listed in

W. J. ROMANOW is associated with the Bell Telephone Laboratories Inc., Murray Hill, N. J.

TN 395E. Manuscript, Oct. 10, 1956.

Table I. Angles Between the Crystallographic Planes of Manganese Bismuthide*

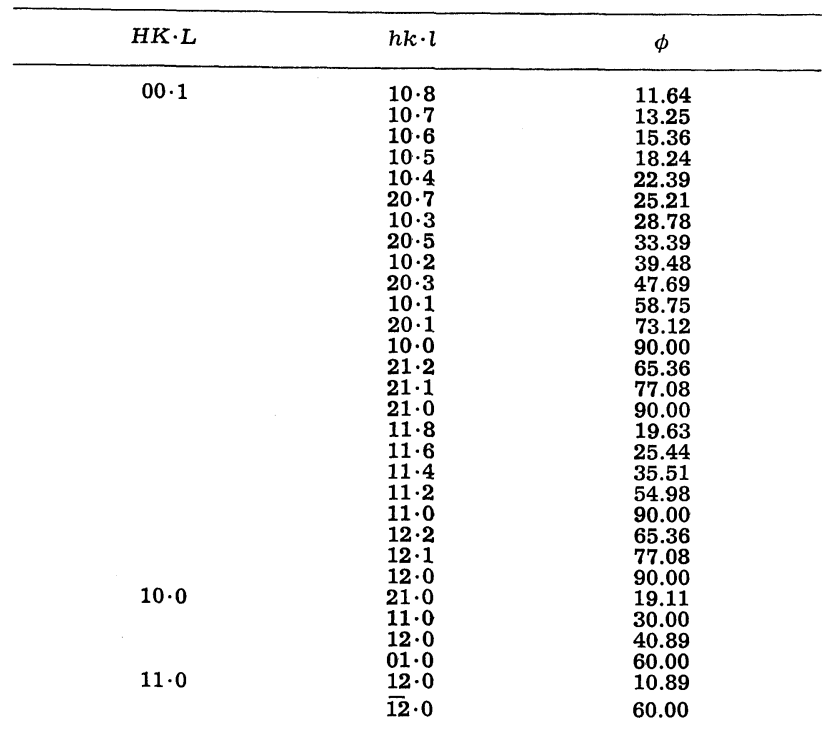

${ }^{*} a_{0}=4.286 \AA, c_{0}=6.116 \AA$, and $c / a=1.427$.
Table I and are those determined by Willis and Rooksby ${ }^{7}$ at $20^{\circ} \mathrm{C}$. More recently published values obtained by both $\mathrm{X}$-ray and neutron diffraction ${ }^{2-4}$ show no difference from these significant to the calculation.

From the crystallographic angles between the basal plane $(00 \cdot 1)$ and the general plane $(h k \cdot l)$ in Table I, an $(00 \cdot 1)$ standard stereographic projection was made for $\mathrm{MnBi}$ which is shown in Fig. 1 .

\section{Acknowledgments}

The author wishes to thank R. G. Treuting and J. N. Hobstetter for their technical assistance, and Miss D. P. Booth for programing the IBM machine for the calculations. He appreciates the opportunity to read the paper of B. W. Roberts of Generad Electric Co. prior to its publication.

\section{References}

${ }^{1} \mathrm{H}$. J. Williams, R. C. Sherwood, and O. L. Boothby: Bulletin Amer. Physical Soc., 1956, vol. 1, p. 132 .

${ }^{2}$ A. U. Seybolt, H. Hansen, B. W. Roberts, and P. Yurcisin: AIME rrans., 1956, vol. 206, p. 605; Journal of METALS, May 1956.

3 R. R. Heikes: Physical Review, 1955, vol. 99, p. 446.
4 B. W. Roberts: A Neutron Diffraction Study of ${ }^{4}$ B. W. Roberts: A Neutron Diffraction Study of the Structures of Manganese Bismuthide, Physical Review, 1956, vol. 104, p. 607 ${ }^{5}$ A. Taylor and S. Leber: AIME Trans., 1954, vol. 200, p. 190;

JouRnal OF Metals, February 1954 . Book Co. New York and London, 1952.

7 B. T. M. Willis and H. P. Rooksby: Proceedings Physical Soc.

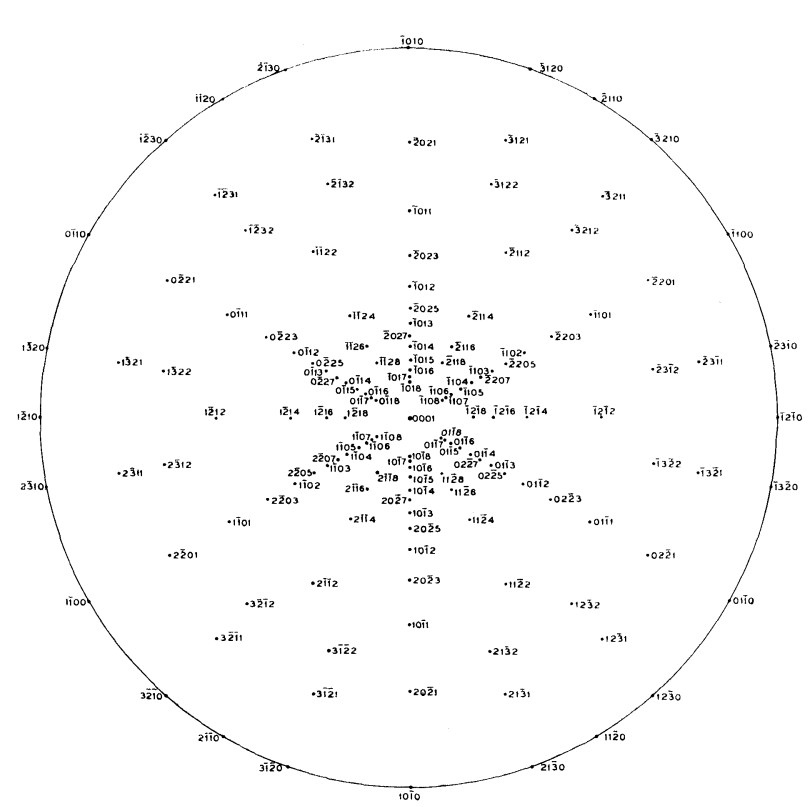

Fig. 1-Standard (00.1) stereographic projection for $\mathrm{MnBi}$; $c / a=1.427$. 